\title{
Occupational, Transport, Leisure-Time, and Overall Sedentary Behaviors and Their Associations with the Risk of Cardiovascular Disease among High-Tech Company Employees
}

\author{
Mei-Lan Liu ${ }^{1}\left(\mathbb{D}\right.$, Chia-Hui Chang ${ }^{1}$, Ming-Chun Hsueh ${ }^{2}$, Yi-Jin $\mathrm{Hu}^{1, *}$ and Yung Liao ${ }^{1,3, *(\mathbb{D})}$ \\ 1 Department of Health Promotion and Health Education, National Taiwan Normal University, 162, \\ Heping East Road Section 1, Taipei 106, Taiwan; 80205005e@ntnu.edu.tw (M.-L.L.); \\ 60605005e@ntnu.edu.tw (C.-H.C.) \\ 2 Graduate Institute of Sport Pedagogy, University of Taipei, Taipei 11153, Taiwan; boxeo@utaipei.edu.tw \\ 3 Adjunct researcher, Faculty of Sport Sciences, Waseda University, 2-579-15, Mikashima, Tokorozawa City \\ Saitama Prefecture 359-1192, Japan \\ * Correspondence: t09016@ntnu.edu.tw (Y.-J.H.); liaoyung@ntnu.edu.tw (Y.L.)
}

Received: 4 December 2019; Accepted: 8 May 2020; Published: 12 May 2020

\begin{abstract}
This study examined the associations of overall and domain-specific (i.e., occupational, transport, and leisure-time) sedentary behaviors with cardiovascular disease (CVD) risk factors among high-tech company employees in Taiwan. A total of 363 participants employed at high-tech companies (mean age \pm standard deviation: $37.4 \pm 7.2$ years) completed a questionnaire administered by email regarding their overall, occupational, transport, and leisure-time sedentary behaviors. Self-reported data of height and weight, blood pressure, blood sugar, and total cholesterol levels were also collected in 2018. An adjusted binary logistic regression model was employed in the analysis. After adjusting for sociodemographic variables, high-tech company employees who used a computer (or Internet) for more than $2 \mathrm{~h}$ per day during their leisure time were more likely to have CVD risk factors (odds ratio: 1.80; 95\% confidence interval: 1.08-3.00). No significant associations with CVD risk factors were detected for total sedentary time, occupational sitting, television viewing time, and transport-related sitting. Despite the nature of cross-sectional design in this study, our findings may have considerable implications for intervention designers and policymakers of Taiwan. Developing effective strategies for limiting leisure-time computer use should be considered for the prevention of CVD among high-tech company employees.
\end{abstract}

Keywords: cardiovascular disease; sedentary behavior; high-tech company; occupational health

\section{Introduction}

Cardiovascular disease (CVD) is a leading cause of death worldwide. The World Health Organization [1] reported that, in 2015, an estimated 17.7 million people died of CVD, accounting for $31 \%$ of deaths globally. For the prevention of CVD, reducing the effects of modifiable physiological risk factors for CVD, such as high blood pressure, diabetes, overweightness or obesity, and high blood cholesterol, through lifestyle and behavioral changes is crucial [1,2]. Physical inactivity, smoking, an unhealthy diet, and sedentary behaviors have been considered to be associated with increased risk of CVD and its related physiological risk factors [3]. WHO and a number of studies have indicated that workplace health promotion programs can be beneficial to employees' health $[4,5]$. In addition, long working hours, shift work, and psychosocial stress at work are the risk factors of CVD [6,7]. Therefore, government regulators and employers need to take action to prevent CVD among workers. 
Sedentary behavior is any waking behavior characterized by an energy expenditure of $\leq 1.5$ metabolic equivalents while in a sitting, reclining, or lying posture [8]. Some studies have provided evidence of a relationship between sedentary behavior and sociodemographic characteristics $[9,10]$. Sedentary behavior was reported to be independently associated with CVD risk, regardless of physical activity levels [11]. Sedentary behavior may occur in a variety of contexts, including during home-based, leisure, occupational, or transport activities [12]. Many studies have provided evidence of a relationship between sedentary behavior and CVD risk [13-15]. Although a review indicated that a greater amount of time spent using technology or sitting is associated with an increased risk of CVD [16], the relationships of other domain-specific sedentary behaviors derived from different contexts with CVD risk factors remain unclear. Some researchers have suggested that different domains of sedentary behavior (i.e., occupational, transport, and leisure) may have distinct associations with health outcomes $[17,18]$. To design effective and tailored intervention strategies for preventing CVD, identifying the roles of different elements of sedentary behavior in CVD risk factors is crucial.

Innovative and high-tech industries have become increasingly successful in modern society [19], and employees working in high-tech companies are more likely to have reduced demands for physical activity and increased demands for prolonged and uninterrupted sedentary behavior (i.e., programming and administrative tasks) with respect to their occupational activity [20]. These employees may also be required to spend more time exhibiting sedentary behavior in other domains (e.g., leisure and transport) in addition to workplace sitting time as a result of high levels of exposure to high-tech products. In this context, Taiwan offers a unique research opportunity because the increasing global demand for mobile devices and access to the Internet has promoted the growth of Taiwan's high-tech industries [21]. To improve the prevention of CVD for this at-risk population of high-tech company employees, this study examined the overall and domain-specific (i.e., occupational, transport, and leisure-time) sedentary behavior of individuals in a sample from Taiwan and the associations of these behaviors with CVD risk factors. We hypothesized that high-tech company employees who engaged in higher overall and domain-specific sedentary behavior were more likely to have CVD risk factors.

\section{Materials and Methods}

\subsection{Participants}

Participants were recruited from June to September 2018 from three Science Parks in Taiwan: Neihu Technology Park, Nangang Software Park, and Oriental Science Park. There were approximately 200,000 people working at these three Science Parks. We selected six companies (about 2700 employees as the target population). Only people aged between 18 to 65 years who were full-time or part-time employed at high-tech companies were recruited. We invited about 1600 employees to join this study via email. Finally, a total of 368 participants responded to our invitation, and 363 of these completed the questionnaire. Convenience sampling was utilized. This study was approved by the National Taiwan Normal University Human Research Ethics Committee (REC 201803HM020).

\subsection{Sedentary Behavior}

The survey components were based on the Sedentary Behavior Questionnaire for the Elderly of Taiwan. The questionnaire had adequate test-retest $(\mathrm{r}=0.74)$ and concurrent validity $(\mathrm{r}=0.52$, $p<0.001$ ) levels [22]. This study evaluated occupational (working or volunteering), transport or driving, leisure-time, and overall sedentary behaviors (e.g., watching TV, videos, or DVDs, using the computer or Internet, reading, engaging in social communication, and eating). Participants self-reported these sedentary behaviors in response to the following questions: "How many days did you engage in the behavior in the last 7 days?" and "How many hours and minutes did you spend engaging in this sedentary behavior on such a day?". The sum of the time spent on engagement in occupational, transport, leisure-time, and overall sedentary behaviors was presented as minutes per day. According to previous studies [23-25], we used the cut-off value of $2 \mathrm{~h} /$ day to dichotomize leisure-time computer 
use and TV viewing time into "high ( $\geq 2 \mathrm{~h} /$ day)" and "low ( $<2 \mathrm{~h} /$ day)" groups. Other sedentary behaviors were categorized as "high" and "low" groups using median minutes per day.

\subsection{CVD Risk Factors}

Traditional CVD risk factors include waist circumference, body mass index (BMI), systolic and diastolic blood pressure, total and high-density lipoprotein cholesterol levels, and glycated hemoglobin levels [26,27]. CVD risk factors in the present study included (1) BMI (body weight and height were converted into BMI values); (2) blood pressure (normal range was 90/60-140/90 $\mathrm{mmHg}$ ); (3) waist circumference (normal range was $<80 \mathrm{~cm}$ for women and $<90 \mathrm{~cm}$ for men); (4) total cholesterol level (normal range was $<200 \mathrm{mg} / \mathrm{dL}$ ); (5) triglyceride level (normal range was $<150 \mathrm{mg} / \mathrm{dL}, 150-200 \mathrm{mg} / \mathrm{dL}$ was borderline high); and (6) fasting blood sugar (normal range was 70-110 mg/dL). All surveyed employees received mandatory physical examinations at their workplace, thus, we asked participants to report the information of waist circumference, body mass index, systolic and diastolic blood pressure, total and high-density lipoprotein cholesterol levels, and fasting blood sugar levels on the basis of most recent physical examination results.

\subsection{Sociodemographic Factors}

In the survey, participants reported their age, sex, marital status (married/divorced/widowed/never married), education level, number of children in the household, nature of their occupation and their employment position, and the presence of any chronic disease (diagnosed by a doctor). Education level was categorized as less than university level (high school/vocational school), university, and master's level and beyond. Presence of children in the household was categorized as yes, no, or expecting. Nature of work was categorized as staff or supervisor, and work position was categorized as administrative work, research and development (R\&D) engineering, on-site operation, and other.

\subsection{Statistical Analysis}

The data of 363 employees who provided information for the study were analyzed. A binary logistic regression was used to estimate odds ratios (ORs) and 95\% confidence intervals (CIs) for the associations between total and domain-specific (occupational, transport, leisure-time) sedentary activity and CVD risk factors. Three models were analyzed. Model 1 was the crude model. Model 2 was adjusted for gender and age. Model 3 was further adjusted for gender, age, marital status, educational level, number of children, work type, and work position. All analyses were performed with SPSS Version 23, and the level of significance was set at $p<0.05$.

\section{Results}

Table 1 presents the sociodemographic characteristics in the total sample. Overall, the mean age (standard deviation) of the respondents was $37.4( \pm 7.2)$ years. In total, $56.7 \%$ of the respondents were men, $62.5 \%$ were younger than 39 years, $54.3 \%$ were married, $55.9 \%$ had an educational level less than university, $55.9 \%$ had no children, $59.8 \%$ worked in R\&D, and $63.9 \%$ were staff. There were four participants $(1.1 \%)$ who had a history of CVD.

Table 2 lists the means and percentages of the sedentary behavior variables. Of the total sitting time, 38\%, 30\%, 15\%, 9\%, and 7\% comprised occupational, other, leisure-time computer use, transport, and TV viewing, respectively. The mean (standard deviation) overall sedentary time was 6088.16 (2687.77) $\mathrm{min} /$ week. Of the five domains, the average amounts of time spent at work (2335.54 $\pm 777.18 \mathrm{~min} /$ week), on other activities (1849.74 $\pm 1567.2 \mathrm{~min} /$ week), using a computer during leisure time (925.21 $\pm 963.69 \mathrm{~min} /$ week), on transport (570.87 $\pm 688.72 \mathrm{~min} /$ week), and on watching TV $(406.60 \pm 437.58 \mathrm{~min} /$ week $)$ are shown in Table 3. 
Table 1. Demographic characteristics of high-tech company employees.

\begin{tabular}{|c|c|c|c|c|c|c|c|}
\hline \multirow{2}{*}{ Variable } & \multirow{2}{*}{ Category } & \multicolumn{2}{|c|}{ Total Sample } & \multicolumn{2}{|c|}{ Without CVD Risk Factors } & \multicolumn{2}{|c|}{ With CVD Risk Factors } \\
\hline & & $n=363$ & $\%$ & $n=125$ & $\%$ & $n=238$ & $\%$ \\
\hline \multirow{2}{*}{ Gender } & Female & 157 & 43.3 & 65 & $52.0 \%$ & 92 & $38.7 \%$ \\
\hline & Male & 206 & 56.7 & 60 & $48.0 \%$ & 146 & $61.3 \%$ \\
\hline \multirow{3}{*}{ Age level } & $\begin{array}{c}\text { Mean 37.7y } \\
(\text { SD 7.1) }\end{array}$ & & & & & & \\
\hline & $<40$ year & 227 & 62.5 & 89 & $71.2 \%$ & 138 & $58.0 \%$ \\
\hline & $\geq 40$ year & 136 & 37.5 & 36 & $28.8 \%$ & 100 & $42.0 \%$ \\
\hline \multirow{2}{*}{$\begin{array}{l}\text { Marital } \\
\text { status }\end{array}$} & Unmarried & 166 & 45.7 & 65 & $52.0 \%$ & 101 & $42.4 \%$ \\
\hline & Married & 197 & 54.3 & 60 & $48.0 \%$ & 137 & $57.6 \%$ \\
\hline \multirow{2}{*}{$\begin{array}{l}\text { Number of } \\
\text { children }\end{array}$} & No child & 203 & 55.9 & 74 & $59.2 \%$ & 129 & $54.2 \%$ \\
\hline & have child & 160 & 44.1 & 51 & $40.8 \%$ & 109 & $45.8 \%$ \\
\hline \multirow{2}{*}{ Job grade } & Staff & 232 & 63.9 & 83 & $66.4 \%$ & 149 & $62.6 \%$ \\
\hline & Supervisor & 131 & 36.1 & 42 & $33.6 \%$ & 89 & $37.4 \%$ \\
\hline \multirow{2}{*}{ Position } & other work & 146 & 40.2 & 53 & $42.4 \%$ & 93 & $39.1 \%$ \\
\hline & R\&D & 217 & 59.8 & 72 & $57.6 \%$ & 145 & $60.9 \%$ \\
\hline \multirow{2}{*}{$\begin{array}{l}\text { Education } \\
\text { level }\end{array}$} & University & 203 & 55.8 & 74 & $59.2 \%$ & 129 & $54.2 \%$ \\
\hline & Master degree or Dr. & 160 & 44.1 & 51 & $40.8 \%$ & 109 & $45.8 \%$ \\
\hline
\end{tabular}

CVD, cardiovascular disease; SD, standard deviation.

Table 2. Descriptive statistical summary of time spent on various sedentary behaviors.

\begin{tabular}{ccc}
\hline Variable & CVD & Average Time (SD) \\
\hline \multirow{2}{*}{ Occupational sitting } & no & $2346.35(768.73)$ \\
& yes & $1762.50(1239.20)$ \\
\hline \multirow{2}{*}{ TV viewing } & no & $404.53(437.30)$ \\
& yes & $480.00(379.47)$ \\
\hline \multirow{2}{*}{ Leisure-time computer use } & no & $920.53(955.96)$ \\
& yes & $1560.00(1409.68)$ \\
\multirow{2}{*}{ Transport-related sitting } & no & $565.62(682.43)$ \\
& yes & $1012.50(819.89)$ \\
\hline \multirow{2}{*}{ Other sitting time } & no & $1840.65(1545.56)$ \\
& yes & $2855.00(3069.64)$ \\
\hline \multirow{2}{*}{ Total sitting time } & no & $6077.67(2652.96)$ \\
& yes & $7670.00(4825.87)$ \\
\hline
\end{tabular}

$\mathrm{SD}$, standard deviation; min/week.

Table 3. The mean of sedentary behavior patterns by with and without CVD risk.

\begin{tabular}{|c|c|c|c|c|c|c|}
\hline \multirow{2}{*}{ Variables } & Total Sample & $\begin{array}{c}\text { Without CVD } \\
\text { Factor }\end{array}$ & With CVD Factors & & & \\
\hline & $\begin{array}{c}n=363(100 \%) \\
\text { Average Time (SD) }\end{array}$ & $\begin{array}{c}n=125(34.4 \%) \\
\text { Average Time (SD) }\end{array}$ & $\begin{array}{c}n=238(65.6 \%) \\
\text { Average Time (SD) }\end{array}$ & $t$ & $d f$ & $P$ \\
\hline Occupational sitting & $2335.54(777.18)$ & $2323.72(749.72)$ & $2341.74(792.70)$ & -0.210 & 361 & 0.332 \\
\hline TV viewing & $406.8(437.58)$ & $370.16(393.69)$ & $426.04(458.57)$ & -1.157 & 361 & 0.089 \\
\hline Leisure-time computer use & $925.21(963.69)$ & $1001.66(1349.89)$ & $885.06(678.54)$ & 1.096 & 361 & 0.002 \\
\hline Transport-related sitting & $570.87(688.72)$ & $600.67(799.21)$ & $555.21(624.18)$ & 0.597 & 361 & 0.436 \\
\hline Other sitting & $1849.74(1567.2)$ & $60.24(118.63)$ & 70.81 (195.52) & 0.549 & -0.553 & 361 \\
\hline Total sitting & $6088.16(2687.77)$ & $6368.68(3394.912)$ & $5940.82(2222.79)$ & 0.017 & 1.443 & 361 \\
\hline
\end{tabular}

SD, standard deviation; min/week.

Table 3 also lists the mean of sedentary behavior patterns without and with CVD risk. The mean (standard deviation) of overall sedentary time without CVD risk and with CVD risk were 6368.68 (3394.912) and 5940.82 (2222.79) $\mathrm{min} /$ week, respectively. Of the five domains, the average amounts of 
time spent at work (occupational sitting) without and with CVD risk, respectively, were 2323.72 (749.72) and 2341.74 (792.70) $\mathrm{min} /$ week; on watching TV were 370.16 (393.69) and 426.04 (458.57) $\mathrm{min} /$ week; on other activities (other sitting) were 60.24 (118.63) and 70.81 (195.52) $\mathrm{min} /$ week; leisure time using a computer were 1001.66 (1349.89) and 885.06 (678.54) min/week; on transport were 600.67 (799.21) and 555.21 (624.18) $\mathrm{min} /$ week. Significant differences between CVD risk groups were only observed in leisure time using a computer $(p<0.05)$.

Table 4 presents the ORs for the associations between overall and domain-specific (i.e., occupational, transport, and leisure-time) sedentary behavior and CVD risk factors among high-tech company employees. In model 1 and model 2, no significant associations between sedentary behaviors and CVD risk factor were observed. In model 3 (full-adjusted model), respondents who reported greater amounts of time spent using computers were more likely to have more than one CVD risk factor (OR $=1.80,95 \%$ $\mathrm{CI}=1.08-3.00 ; p=0.02$ ) compared with those with lower amounts of computer use time. No significant association with CVD risk factors was observed for total sedentary time $(p=0.10)$, occupational sitting time $(p=0.43)$, TV viewing time $(p=0.14)$, or transport-related sitting time $(p=0.75)$.

Table 4. Summary of the logistic regression analysis of time spent engaged in sedentary behavior and cardiovascular disease risk factors.

\begin{tabular}{|c|c|c|c|c|c|c|c|c|c|c|}
\hline \multirow{3}{*}{ Variable } & \multirow{3}{*}{ Category } & \multicolumn{3}{|c|}{ Model 1} & \multicolumn{3}{|c|}{ Model 2} & \multicolumn{3}{|c|}{ Model 3} \\
\hline & & \multicolumn{3}{|c|}{ CVD Risk Factors } & \multicolumn{3}{|c|}{ CVD Risk Factors } & \multicolumn{3}{|c|}{ CVD Risk Factors } \\
\hline & & OR & $95 \% \mathrm{CI}$ & $p$-Value & OR & $95 \% \mathrm{CI}$ & $p$-Value & OR & $95 \% \mathrm{CI}$ & $p$-Value \\
\hline \multirow{2}{*}{$\begin{array}{l}\text { Total sitting } \\
\text { time }\end{array}$} & Low & 1.00 (ref.) & & & 1.00 (ref.) & & & 1.00 (ref.) & & \\
\hline & High & 0.84 & $0.92-2.45$ & 0.53 & 0.95 & $0.53-1.67$ & 0.85 & 1.50 & $0.92-2.45$ & 0.10 \\
\hline \multirow{2}{*}{$\begin{array}{l}\text { Occupational } \\
\text { sitting }\end{array}$} & Low & 1.00 (ref.) & & & 1.00 (ref.) & & & 1.00 (ref.) & & \\
\hline & High & 0.82 & $0.51-1.32$ & 0.42 & 0.82 & $0.50-1.33$ & 0.42 & 0.81 & $0.86-2.89$ & 0.43 \\
\hline \multirow{2}{*}{ TV viewing } & Low & 1.00 (ref.) & & & 1.00 (ref.) & & & 1.00 (ref.) & & \\
\hline & High & 1.61 & $0.89-2.93$ & 0.12 & 1.47 & $0.80-2.71$ & 0.22 & 1.57 & $0.86-2.89$ & 0.14 \\
\hline \multirow{2}{*}{$\begin{array}{l}\text { Leisure-time } \\
\text { computer use }\end{array}$} & Low & 1.00 (ref.) & & & 1.00 (ref.) & & & 1.00 (ref.) & & \\
\hline & High & 1.48 & $0.90-2.42$ & 0.12 & 1.62 & $0.97-2.71$ & 0.07 & 1.80 & $1.08-3.00$ & $0.02 *$ \\
\hline \multirow{2}{*}{$\begin{array}{l}\text { Transport-related } \\
\text { sitting }\end{array}$} & Low & 1.00 (ref.) & & & 1.00 (ref.) & & & 1.00 (ref.) & & \\
\hline & High & 1.36 & $0.86-2.17$ & 0.19 & 1.30 & $0.81-2.08$ & 0.28 & 1.08 & $0.65-1.78$ & 0.75 \\
\hline
\end{tabular}

\section{Discussion}

To the best of our knowledge, this is the first study to examine the associations of overall and domain-specific (i.e., occupational, transport, and leisure-time) sedentary behavior with CVD risk factors in the specific work population of high-tech company employees. The main finding of this study is that spending more than $2 \mathrm{~h}$ per day on leisure-time computer use was associated with a greater likelihood of having more than one CVD risk factor among high-tech company employees, after physical activity and other confounders were controlled for. No significant associations were observed for total sedentary time, occupational sitting, transport-related sitting, and TV viewing. Therefore, these findings may have profound implications for workplace intervention designers and policymakers; specifically, effective strategies should prioritize the reduction of leisure-time computer use rather than that of occupational or transport sitting to reduce the risk of CVD among high-tech company employees. The government or employers can promote workers to attend more activities after work, such as exercise programs or social activity, in order to replace their time spent on leisure-time computer use.

Consistent with several other studies [17,28,29], leisure-time sedentary behavior poses greater risk to cardio-metabolic health than do total sedentary time and other domains of sedentary behavior. Our results also reveal that between the two types of leisure-time sedentary behavior, only leisure-time computer use, and not TV viewing, was associated with an increased likelihood of having CVD risk factors. Although TV viewing is considered a dominant leisure-time sedentary behavior with negative 
effects on cardio-metabolic health [22,30,31], it is possible that with the evolution of modern technology, computer use (including Internet and smartphone use) has become a more prevalent leisure-time activity in the adult population, which may increase the risk of developing CVD risk factors. Indeed, the participants of this study spent higher time on leisure-time computer use ( $925.21 \pm 963.69 \mathrm{~min} /$ week $)$ than TV viewing ( $406.60 \pm 437.58 \mathrm{~min} /$ week). Thus, possible explanations for the positive associations between leisure-time computer use and CVD risk factors are that leisure-time computer use is a prolonged sedentary activity characterized by uninterrupted breaks and low energy expenditure $[32,33]$ and that it is possibly related to other unhealthy behaviors, such as unhealthy eating and watching TV [34]. Thus, our findings may highlight the value of limiting leisure-time computer use to less than $2 \mathrm{~h}$ per day among high-tech company employees and may provide evidence for future guidelines on CVD prevention.

Another critical finding of this study is that no significant associations were observed between CVD risk factors and total, occupational, or transport-related sitting among high-tech company employees. There are several possible explanations for this result. First, regarding total sedentary time, other studies have reported that specific domains of sedentary behavior have different associations with health outcomes $[17,18,35]$. Therefore, the effects of domain-specific sedentary behavior may be negligible in total sedentary time with respect to CVD risk factors. Second, regarding transport-related sitting, compared with Western countries, the amount of time spent in transport may occupy a smaller portion of daily sedentary time for the participants in our study, thus explaining its lack of association with CVD risk factors. Third, in contrast to several related studies that have reported a positive relationship between occupational sitting and CVD risk factors [36-38], our results show no significant associations. This inconsistency could be attributable to our cross-sectional design and the lack of consideration for breaks in occupational sedentary behavior. Therefore, future prospective studies using both objective and subjective measures should further explore this topic to confirm our results.

Several limitations of the present study should be considered. First, because of the cross-sectional design of this study, a causal link between sedentary behavior and CVD risk cannot be assumed. Second, several confounding factors, such as smoking, dietary behavior, and alcohol consumption, were not included in the present study. Third, in our study, we examined the CVD risk factors all together but not one by one due to the limited number of each risk factor. Fourth, the measurements in the present study, including sedentary behavior and status of CVD risk factors, were self-reported and could be subject to bias. In addition, we measured sedentary behavior only in the previous seven days, thus limiting the ability to assess long-term lifestyles. Finally, since gender is an important moderator between sedentary behavior and CVD risk factors, this study is limited in not examining these associations by gender. Future studies are warranted to examine gender-specific associations between sedentary behavior and CVD risk factors among high-tech company employees.

\section{Conclusions}

Despite the cross-sectional nature and small sample size in this study, our results support the view that workers in high-tech companies need to be aware that sedentary behaviors, particularly leisure-time computer use, could be one of the risk factors of CVD, in the context of Taiwan. These findings may have considerable implications for local policymakers and designers of workplace interventions. In addition to programs of exercise and healthy dieting, priority should be given to developing effective strategies for limiting leisure-time computer use.

Author Contributions: Conceptualization, Y.-J.H. and Y.L.; methodology, M.-L.L, C.-H.C. and Y.L.; software, C.-H.C. and Y.L.; formal analysis, C.-H.C. and Y.L.; investigation, M.-L.L.; resources, M.-L.L., and Y.-J.H.; writing-original draft preparation, M.-L.L., C.-H.C. and Y.L.; writing-review and editing, M.-L.L., M.-C.H., C.-H.C., Y.-J.H., and Y.L.; visualization, M.-L.L.; supervision, Y.-J.H.; project administration, M.-L.L.; All authors have read and agreed to the published version of the manuscript.

Funding: M.-C.H. received a personal grant from the Ministry of Science and Technology of Taiwan (MOST 108-2410-H-845-031). 
Conflicts of Interest: The authors declare no conflict of interest. The Ministry of Science and Technology of Taiwan was not involved in the study design, data collection process, analysis, interpretation, or writing of this manuscript.

\section{References}

1. WHO. Cardiovascular Diseases (CVDs). Available online: https://www.who.int/news-room/fact-sheets/ detail/cardiovascular-diseases-(cvds) (accessed on 28 March 2020).

2. Wong, N.D.; Moran, A.E. The U.S. Prevention of Cardiovascular Disease Guidelines and Implications for Implementation in LMIC. Glob. Heart 2014, 9, 445-455. [CrossRef] [PubMed]

3. Piepoli, M.F.; Hoes, A.W.; Agewall, S.; Albus, C.; Brotons, C.; Catapano, A.L.; Deaton, C. 2016 European Guidelines on cardiovascular disease prevention in clinical practice: The Sixth Joint Task Force of the European Society of Cardiology and Other Societies on Cardiovascular Disease Prevention in Clinical Practice (constituted by representatives of 10 societies and by invited experts) Developed with the special contribution of the European Association for Cardiovascular Prevention \& Rehabilitation (EACPR). Eur. Heart J. 2016, 37, 2315-2381. [PubMed]

4. Coffeng, J.K.; Van Der Ploeg, H.P.; Castellano, J.M.; Fernández-Alvira, J.M.; Ibanez, B.; García-Lunar, I.; Van Der Beek, A.J.; Fernández-Ortiz, A.; Mocoroa, A.; García-Leal, L.; et al. A 30-month worksite-based lifestyle program to promote cardiovascular health in middle-aged bank employees: Design of the TANSNIP-PESA randomized controlled trial. Am. Heart J. 2017, 184, 121-132. [CrossRef] [PubMed]

5. Martin, A.; Fitzsimons, C.; Jepson, R.; Saunders, D.H.; Van Der Ploeg, H.P.; Teixeira, P.J.; Gray, C.M.; Mutrie, N. Interventions with potential to reduce sedentary time in adults: Systematic review and meta-analysis. Br. J. Sports Med. 2015, 49, 1056-1063. [CrossRef] [PubMed]

6. Fishta, A.; Backé, E.-M. Psychosocial stress at work and cardiovascular diseases: An overview of systematic reviews. Int. Arch. Occup. Environ. Health 2015, 88, 997-1014. [CrossRef] [PubMed]

7. Kivimaki, M.; Jokela, M.; Nyberg, S.T.; Singh-Manoux, A.; Fransson, E.; Alfredsson, L.; Bjorner, J.B.; Borritz, M.; Burr, H.; Casini, A.; et al. Long working hours and risk of coronary heart disease and stroke: A systematic review and meta-analysis of published and unpublished data for 603838 individuals. Lancet 2015, 386, 1739-1746. [CrossRef]

8. Tremblay, M.S.; Participants, O.B.O.S.T.C.P.; Aubert, S.; Barnes, J.D.; Saunders, T.J.; Carson, V.; Latimer-Cheung, A.E.; Chastin, S.F.M.; Altenburg, T.; Chinapaw, M.J.; et al. Sedentary Behavior Research Network (SBRN)-Terminology Consensus Project process and outcome. Int. J. Behav. Nutr. Phys. Act. 2017, 14, 75. [CrossRef]

9. Celis-Morales, C.; Salas, C.; Alduhishy, A.; Sanzana, R.; Martínez, M.A.; Leiva, A.; Diaz, X.; Martínez, C.; Álvarez, C.; Zamora, J.L.; et al. Socio-demographic patterns of physical activity and sedentary behaviour in Chile: Results from the National Health Survey 2009-2010. J. Public Health 2015, 38, e98-e105. [CrossRef]

10. Lakerveld, J.; Loyen, A.; Schotman, N.; Peeters, C.F.; Cardon, G.; Van Der Ploeg, H.P.; Lien, N.; Chastin, S.; Brug, J. Sitting too much: A hierarchy of socio-demographic correlates. Prev. Med. 2017, 101, 77-83. [CrossRef]

11. Alves, A.J.; Viana, J.; Cavalcante, S.L.; Oliveira, N.L.; Duarte, J.A.; Mota, J.; Oliveira, J.; Ribeiro, F. Physical activity in primary and secondary prevention of cardiovascular disease: Overview updated. World J. Cardiol. 2016, 8, 575-583. [CrossRef]

12. Owen, N.; Salmon, J.; Koohsari, M.J.; Turrell, G.; Giles-Corti, B. Sedentary behaviour and health: Mapping environmental and social contexts to underpin chronic disease prevention. Br. J. Sports Med. 2014, 48, 174-177. [CrossRef] [PubMed]

13. Cabanas-Sánchez, V.; Guallar-Castillon, P.; Higueras-Fresnillo, S.; Rodríguez-Artalejo, F.; Martinez-Gomez, D. Changes in Sitting Time and Cardiovascular Mortality in Older Adults. Am. J. Prev. Med. 2018, 54, 419-422. [CrossRef] [PubMed]

14. Hallman, D.M.; Krause, N.; Jensen, M.T.; Gupta, N.; Jørgensen, M.B.; Holtermann, A. Objectively Measured Sitting and Standing in Workers: Cross-Sectional Relationship with Autonomic Cardiac Modulation. Int. J. Environ. Res. Public Health 2019, 16, 650. [CrossRef] [PubMed] 
15. Young, D.R.; Hivert, M.-F.; Alhassan, S.; Camhi, S.M.; Ferguson, J.F.; Katzmarzyk, P.T.; Lewis, C.E.; Owen, N.; Perry, C.K.; Siddique, J.; et al. Sedentary Behavior and Cardiovascular Morbidity and Mortality: A Science Advisory From the American Heart Association. Circulation 2016, 134, e262-e279. [CrossRef]

16. Ford, E.S.; Caspersen, C.J. Sedentary behaviour and cardiovascular disease: A review of prospective studies. Int. J. Epidemiol. 2012, 41, 1338-1353. [CrossRef]

17. Hsueh, M.-C.; Liao, Y.; Chang, S.-H. Associations of Total and Domain-Specific Sedentary Time With Type 2 Diabetes in Taiwanese Older Adults. J. Epidemiol. 2016, 26, 348-354. [CrossRef]

18. Mahmood, S.; MacInnis, R.J.; English, D.R.; Karahalios, A.; Lynch, B.M. Domain-specific physical activity and sedentary behaviour in relation to colon and rectal cancer risk: A systematic review and meta-analysis. Int. J. Epidemiol. 2017, 46, 1797-1813. [CrossRef]

19. Dunstan, D.W.; Healy, G.N.; Sugiyama, T.; Owen, N. Too much sitting: The population health science of sedentary behavior. Eur. Endocrinol. 2010, 6, 19-23. [CrossRef]

20. Parry, S.; Straker, L. The contribution of office work to sedentary behaviour associated risk. BMC Public Health 2013, 13, 296. [CrossRef]

21. Lin, R.-T.; Christiani, D.C.; Kawachi, I.; Chan, T.-C.; Chiang, P.-H.; Chan, C.-C. Increased Risk of Respiratory Mortality Associated with the High-Tech Manufacturing Industry: A 26-Year Study. Int. J. Environ. Res. Public Health 2016, 13, 557. [CrossRef]

22. Ku, P.-W.; Sun, W.-J.; Chen, L.-J. Development of the Sedentary Behavior Questionnaire for the Elderly. Sports Exerc. Res. 2016, 18, 41-55. [CrossRef]

23. Grøntved, A.; Hu, F.B. Television viewing and risk of type 2 diabetes, cardiovascular disease, and all-cause mortality: A meta-analysis. JAMA 2011, 305, 2448-2455. [CrossRef] [PubMed]

24. Jakes, R.W.; Day, N.E.; Khaw, K.-T.; Luben, R.N.; Oakes, S.; Welch, A.; Bingham, S.; Wareham, N.J. Television viewing and low participation in vigorous recreation are independently associated with obesity and markers of cardiovascular disease risk: EPIC-Norfolk population-based study. Eur. J. Clin. Nutr. 2003, 57, 1089-1096. [CrossRef] [PubMed]

25. Thomée, S.; Lissner, L.; Hagberg, M.; Grimby-Ekman, A. Leisure time computer use and overweight development in young adults-A prospective study. BMC Public Health 2015, 15, 839. [CrossRef] [PubMed]

26. Carter, S.; Hartman, Y.; Holder, S.; Thijssen, D.H.; Hopkins, N.D. Sedentary Behavior and Cardiovascular Disease Risk. Exerc. Sport Sci. Rev. 2017, 45, 80-86. [CrossRef]

27. Stamatakis, E.; Hamer, M.; Tilling, K.; Lawlor, D. Sedentary time in relation to cardio-metabolic risk factors: Differential associations for self-report vs accelerometry in working age adults. Int. J. Epidemiol. 2012, 41, 1328-1337. [CrossRef]

28. Chau, J.Y.; Van Der Ploeg, H.P.; Merom, D.; Chey, T.; Bauman, A. Cross-sectional associations between occupational and leisure-time sitting, physical activity and obesity in working adults. Prev. Med. 2012, 54, 195-200. [CrossRef]

29. Saidj, M.; Jørgensen, T.; Jacobsen, R.K.; Linneberg, A.; Oppert, J.-M.; Aadahl, M. Work and leisure time sitting and inactivity: Effects on cardiorespiratory and metabolic health. Eur. J. Prev. Cardiol. 2015, 23, 1321-1329. [CrossRef]

30. Hu, F.B.; Li, T.Y.; Colditz, G.A.; Willett, W.C.; Manson, J.E. Television Watching and Other Sedentary Behaviors in Relation to Risk of Obesity and Type 2 Diabetes Mellitus in Women. JAMA 2003, 289, 1785-1791. [CrossRef]

31. Sugiyama, T.; Healy, G.; Dunstan, D.W.; Salmon, J.; Owen, N. Is Television Viewing Time a Marker of a Broader Pattern of Sedentary Behavior? Ann. Behav. Med. 2008, 35, 245-250. [CrossRef]

32. Levine, J.A.; Weg, M.V.; Hill, J.O.; Klesges, R.C. Non-Exercise Activity Thermogenesis. Arter. Thromb. Vasc. Boil. 2006, 26, 729-736. [CrossRef] [PubMed]

33. Levine, J.A.; Lanningham-Foster, L.M.; McCrady, S.K.; Krizan, A.C.; Olson, L.R.; Kane, P.H.; Jensen, M.D.; Clark, M.M. Interindividual Variation in Posture Allocation: Possible Role in Human Obesity. Science 2005, 307, 584-586. [CrossRef] [PubMed]

34. Hu, F.B.; Leitzmann, M.F.; Stampfer, M.J.; Colditz, G.A.; Willett, W.C.; Rimm, E.B. Physical activity and television watching in relation to risk for type 2 diabetes mellitus in men. Arch. Intern. Med. 2001, 161, 1542-1548. [CrossRef] [PubMed]

35. De Rezende, L.F.M.; Rey-López, J.; Matsudo, V.K.R.; Luiz, O.D.C. Sedentary behavior and health outcomes among older adults: A systematic review. BMC Public Health 2014, 14, 333. [CrossRef] [PubMed] 
36. Jalayondeja, C.; Jalayondeja, W.; Mekhora, K.; Bhuanantanondh, P.; Dusadi-Isariyavong, A.; Upiriyasakul, R. Break in Sedentary Behavior Reduces the Risk of Noncommunicable Diseases and Cardiometabolic Risk Factors among Workers in a Petroleum Company. Int. J. Environ. Res. Public Health 2017, 14, 501. [CrossRef] [PubMed]

37. Nam, J.Y.; Kim, J.; Cho, K.H.; Choi, Y.; Choi, J.W.; Shin, J.; Park, E.-C. Associations of sitting time and occupation with metabolic syndrome in South Korean adults: A cross-sectional study. BMC Public Health 2016, 16, 943. [CrossRef]

38. Oyeyemi, A.; Adeyemi, O. Relationship of physical activity to cardiovascular risk factors in an urban population of Nigerian adults. Arch. Public Health 2013, 71, 6. [CrossRef]

C 2020 by the authors. Licensee MDPI, Basel, Switzerland. This article is an open access article distributed under the terms and conditions of the Creative Commons Attribution (CC BY) license (http://creativecommons.org/licenses/by/4.0/). 